\title{
OS DESAFIOS DE GESTÃO PARA A INCORPORAÇÃO DE NOVAS TECNOLOGIAS DIGITAIS NOS SERVIÇOS PÚBLICOS de Radiodifusão do Brasil a de Portugal
}

\author{
Carlos Eduardo Esch \& Mariana Martins de Carvalho
}

\begin{abstract}
Resumo
As tecnologias digitais e o surgimento de inovadores serviços de comunicação online estão definindo um contexto desafiador para os gestores dos meios de comunicação de modo geral e, em particular, para os que administram os sistemas públicos de radiodifusão. Esse contexto tem impelido esses profissionais a pensarem e estabelecerem um conjunto de ações cujo objetivo fundamental é modelar, em alguma medida, estratégias com o objetivo de fazer com que estas instituições produzam, divulguem e ofertem conteúdos midiáticos através de novas plataformas e, assim, reestabeleçam e renovem seus vínculos de consumo com distintos perfis de público. Um cenário configurado a partir da disponibilização cada vez mais acentuada de opções midiáticas virtuais aos usuários, e que tem levado os meios de comunicação públicos a enfrentarem perdas representativas de fatias de audiências, situação que pode, em circunstâncias limites, colocar em cheque a legitimidade social deste tipo de radiodifusão, o próprio cumprimento da sua missão e relegá-la a um plano de menor relevância perante os cidadãos. $O$ texto analisa os desafios de gestão que se apresentam para os serviços públicos de radiodifusão do Brasil e de Portugal para incorporarem as novas tecnologias e se fazerem presentes perante seus potenciais públicos no ambiente virtual.
\end{abstract}

\section{Palavras-chave}

Radiodifusão pública; gestão; digitalização; convergência; comunicação online

\section{UM CONTEXTO DE MUDANÇAS}

Os sistemas públicos de radiodifusão existentes na América Latina e na Europa estão atravessando um período histórico marcado por desafios resultantes de grandes mudanças vivenciadas em seus distintos cenários nacionais. Nas últimas décadas, o rol de transformações passou pelas questões políticas sobre o desenho regulatório, o modelo de financiamento para cada contexto nacional e alcançou, de modo especial, as estratégias que estão sendo adotadas para o enfrentamento dos desafios comuns impostos a todos pelas tecnologias digitais que expandiram o mundo das comunicações para o amplo território das redes virtuais (Arons de Carvalho, 2009).

Nos últimos vinte anos, assistiu-se a uma multiplicação de plataformas e tecnologias de distribuição, como a televisão digital, a IPTV (televisão pela Internet), a televisão móvel e o vídeo sob demanda. Incrementou-se significativamente a concorrência a partir da entrada no mercado de novos operadores como as empresas de Internet, por exemplo. A evolução tecnológica permitiu ainda o aparecimento de novos serviços de comunicação, informação e entretenimento online e sob demanda. 
Neste complexo cenário de mudanças, a prestação de serviços audiovisuais tende a convergir e assim, cada vez mais, os consumidores podem obter múltiplos serviços através de diferentes plataformas virtuais ou dispositivos móveis. $\mathrm{O}$ advento da multiplicação dos serviços audiovisuais levou à natural fragmentação das audiências anteriormente registradas na mídia dita convencional.

Ao mesmo tempo, o modelo tradicional de consumo midiático - em boa medida passivo - está gradualmente dando lugar a uma outra forma de participação, em algumas situações, mais ativa, e, de certa forma, com um maior controle do conteúdo ao qual o usuário deseja ter acesso. Neste ambiente de transformação, gestores das empresas públicas de radiodifusão têm buscado diversificar formas de entrega de conteúdos para novas plataformas de distribuição, expandindo assim as possibilidades de experiências de consumo proporcionadas pela ubiquidade da TV (Serra, 2015). Para tanto, os gestores estão sendo levados, cada vez mais, a tentar decifrar e compreender a dinâmica que marca o funcionamento do ágil e mutante "ecossistema virtual", seus serviços, redes e usuários.

Dessa forma, pode-se considerar que o enfrentamento das inovações tecnológicas e suas consequências é um desafio comum e fundamental que se apresenta a todos os serviços de radiodifusão, mas especialmente aos de natureza pública, tanto na Europa, quanto na América Latina e, em particular, no Brasil e em Portugal. Enfrentá-lo com relativo êxito pode significar na Europa a possibilidade de reinventar a radiodifusão pública e renovar laços sociais de pertencimento e identidade (Wolton, 2006). Já no contexto brasileiro, pode ser um instrumento para superar, em alguma medida, a enorme invisibilidade social que a radiodifusão pública ainda apresenta. O caráter inovador e a capacidade de alcançar, bem como, fidelizar públicos mais jovens fazem do espaço virtual uma potencial ferramenta para fomentar a aproximação e a publicização dos meios públicos perante audiências que, até o momento, não consideram TVs e rádios públicas como opções do seu menu midiático.

O êxito de gestores da mídia pública ao se defrontarem com esse ambiente tecnológico e suas exigências e possibilidades, ganha maior importância ao considerarmos a relevância que a radiodifusão pública pode alcançar nos contextos nacionais. Apesar do relativo valor econômico que lhe é inerente, teoricamente não pode ser comparada a qualquer outro tipo de serviço prestado pelas esferas estatais em qualquer regime. Pela sua própria natureza, tendencialmente oferece informações e conteúdos seguindo princípios como diversidade, pluralidade, diferenciação e universalidade com potencial capacidade de orientar e influenciar a opinião pública (Unesco, 2001). Portanto, a atuação dos entes públicos de radiodifusão frente ao novo cenário implica que seus gestores busquem repensar e remodelar modos de operação destas instituições.

\section{O DESAFIO PRIMORDIAL: A PROPAGAÇÃo DE CONTEÚdOS PELA REDE}

Estamos em um momento da história no qual um conjunto de práticas sociais e culturais, somadas as inovações tecnológicas digitais correlatas que cresceram em torno delas, constituem o que se denominou como cultura ligada em rede (Jenkins, Green \& 
Ford, 2014). Essas práticas que entrelaçam as pessoas de muitas maneiras não surgiram somente a partir do desenvolvimento tecnológico. Os fatos ao redor dos acontecimentos sempre geraram interesse e promoveram conversações entre as pessoas ao longo dos tempos. Contudo, a circulação de conteúdos que acontece agora, em um mundo profundamente dependente da comunicação virtual e cada vez mais apoiado na tecnologia digital, se diferencia significativamente das formas de trocas que aconteciam, até mesmo, na recente era analógica. A marca contemporânea da comunicação passou a ser a instantaneidade, a amplitude e a velocidade de alcance das informações, muitas das quais alimentam as ferramentas de contato social que proliferam atualmente pela rede.

A reflexão sobre essas novas circunstâncias é importante e, sobretudo, estratégica. Afinal, a rede que interliga computadores, pessoas e instituições em todo o mundo, gera um ambiente original no qual novas formas de sentir e vivenciar as múltiplas relações de caráter institucional e pessoal são estabelecidas de forma reiterada e cotidiana. Essa condição termina gerando um cenário profundamente dinâmico já que as formas de relacionamento e os modos de consumo estão em franca transformação. Na esfera midiática a transmissão de conteúdos não ocorre mais somente pelas vias tradicionais, ou seja, aquelas propiciadas pelas ondas eletromagnéticas e pela emissão centrada na lógica produtiva/comercial da radiodifusão, sintetizada a partir do conceito básico de um emissor que transmite conteúdos para vários receptores.

O desenvolvimento da tecnologia digital permitiu as pessoas poderem interagir através das diversas ferramentas sociais disponibilizadas na rede. Dessa forma, o processo comunicacional foi potencializado pela quantidade e alcance das mensagens que passaram a circular em um verdadeiro emaranhado de canais que se intercomunicam. Nesse processo intensivo, os conteúdos sofrem diversas alterações ao serem retrabaIhados por inúmeros usuários distribuidores ou redistribuidores a partir de suas emoções, perspectivas, valores, simpatias, rejeições e interesses. Esse tráfego de mensagens fomenta o processo de ressignificação dos conteúdos perante os próprios usuários da rede sejam eles indivíduos, grupos, movimentos ou instituições. Essa é uma mudança fundamental para se pensar de modo realista, e por que não dizer eficaz, esse novo universo virtual no qual também se dá a distribuição de conteúdos midiáticos hojeı.

Para pensarmos essas questões, estabelecemos um diálogo com alguns conceitos e reflexões propostas por Jenkins, Green e Ford (2014) ao elaborarem a ideia de propagabilidade. Essa perspectiva pressupõe uma concepção que considera que "o processo de circulação de conteúdos gera significados e agrega valor aos conteúdos que configuram a mídia atual. Nesse contexto, uma ideia fundamental para pensar os meios de comunicação em geral, e particularmente os virtuais, é a de que se algo não se propaga, está morto, sem existência" (Jenkins et al., 2014, p. 23).

A ideia de que o conteúdo produzido e não propagado pela rede, ou até mesmo, na antiga lógica da radiodifusão está fadado a morrer, é uma questão fundamental para os

\footnotetext{
'Exemplo dessa mudança pode ser verificado através dos dados coletados pelo estudo elaborado pela empresa de consultoria tecnológica Accenture em 13 países e que indicou que no Brasil $77 \%$ dos usuários de internet acessam a rede através de aparatos móveis. Retirado de http://exame.abril.com.br/tecnologia/noticias/africa-do-sul-e-brasil-lideram-acesso-a-internet-movel.
} 
gestores de entidades públicas como a RTP e a EBC. Em um ambiente no qual a concepção de propagabilidade esta relacionada com a capacidade que as entidades de radiodifusão pública têm de promoverem o consumo virtual de seus conteúdos, um dos maiores desafios a serem enfrentados é a conquista e a manutenção de níveis satisfatórios de audiência. Ou seja, estar presente na rede e adquirir capacidade de se fazer notar neste ambiente através da disponibilização de conteúdos que circulem e que gerem respostas nos internautas. Nessa linha de raciocínio, é importante para a análise considerar que os entes públicos RTP e EBC são entidades que apresentam duas grandes dimensões que convivem e que ainda deverão conviver, de modo complementar, durante um tempo significativo de suas histórias.

A primeira delas é calcada na lógica radiodifusora, ou seja, aquela na qual se situam os canais tradicionais de radiodifusão como são as televisões de canal aberto e as suas emissoras de rádio. A outra dimensão diz respeito ao ambiente alimentado pela perspectiva da tecnologia da informação e pela lógica do virtual e da convergência. Essa dimensão já existe nas duas instituições como uma área de atuação, inclusive com espaços administrativos e gerenciais próprios quase sempre definido a partir do conceito multimídia. No entanto, o desenvolvimento da concepção do que venha a ser o espaço multimídia e, principalmente, o estágio de desenvolvimento das ações neste ambiente, se apresentam diferenciadas entre RTP e EBC em face da trajetória histórica de cada uma delas e de características internas originárias de facilidades e dificuldades de gestão e de orçamento apresentadas pelas duas instituições.

Em um ambiente comunicacional de crescente propagabilidade, a chamada área multimídia dos entes públicos necessita ser incrementada de maneira ampla, articulada, sustentável e vigorosa sob pena das entidades perderem o trem da história virtual. O desenvolvimento da tecnologia da informação e o conjunto de conhecimentos que podem ser gerados por esse segmento vão muito além da dinâmica funcional de ferramentas como os aplicativos. Deve gerar um corpo de saberes que permita a entidade, sobretudo, compreender as transformações tecnológicas e virtuais, antever mudanças e conhecer - o mais profundo possível - as múltiplas audiências virtuais contemporâneas. Essa dimensão operacional deve ser uma espécie de "consciência virtual/digital", ou seja, um segmento privilegiado das empresas que acumule conhecimentos sobre a propagação das mensagens no atual universo digital midiático e, sobretudo, adquira capacidade para elaborar estratégias de ação relativas à produção e distribuição de conteúdos junto ao espaço virtual e aos seus usuários.

A perspectiva da propagabilidade leva em consideração um conjunto de questões fundamentais para a reflexão que o conceito propõe, e que abordam desde a existência e a forma como os recursos técnicos digitais facilitam a circulação de alguns conteúdos em comparação com outros, como as estruturas econômicas sustentam ou restringem essa circulação, até as características que fazem com que textos midiáticos despertem o interesse e a vontade de um grupo em compartilhar material através das redes sociais que ligam as pessoas através do consumo e do compartilhamento de informação (Jenkins et al., 2014). Os autores defendem ainda, o estabelecimento de uma cultura 
participativa que se manifesta no virtual e que está baseada na concepção de que as diversas comunidades que estão ligadas colaborativamente por meio das redes, exercem papéis e promovem formas de circulação de conteúdos nas mídias a partir dessa atuação e da ideia de adequação que projetam nesses canais. Com isso, o público ganha um significado bem mais representativo para a circulação de conteúdos do que o determinado pela lógica da radiodifusão tradicional. Situação que faz com que produtores e comunicadores corporativos de distintos perfis estejam mais atentos para a necessidade de ouvir internautas e de compreender seus desejos e anseios, de modo a proporcionar, através da produção de conteúdos, algum tipo de resposta ativa para as distintas demandas apresentadas pelos usuários da rede.

\section{O CONTEXTO DE ANÁLISE}

Para analisar os desafios que os gestores dos entes públicos de radiodifusão consideram mais relevantes para o desenvolvimento de suas ações no ambiente virtual, julgamos necessário partir de uma leitura básica da forma como, até o momento, têm sido levadas a cabo as ações digitais/virtuais que estão em curso nessas instituições. Para isso, fizemos uma análise de como estão materializadas esse conjunto de ações nos seus respectivos portais institucionais disponibilizados na internet pela EBC (www. ebc.com.br) e pela RTP (www.rtp.pt) no período de setembro e outubro de 2015. Portanto, nossa análise parte do levantamento de ações que considera o nível de convergência dos meios e a necessária adaptação de usos, formatos, linguagens e distribuição de conteúdos midiáticos adotados pelos entes em seus portais². A partir dessa leitura, realizamos entrevistas com os profissionais responsáveis ${ }^{3}$ por desenvolver e implantar mecanismos para a produção e distribuição de conteúdos multimídia em cada um dos entes públicos.

Dessa maneira, acreditamos que os dois portais analisados sinalizam, em alguma medida, como as instituições e seus gestores estão buscando e conseguindo atuar no campo das novas tecnologias digitais e, em boa medida, a importância que já atribuem a essas inovações para o desenvolvimento e sobrevivência dos seus canais públicos de radiodifusão. Os dados encontrados nos permitiram apreciá-los, inicialmente, a partir de duas percepções: a convergência incipiente da EBC e a em evolução, no caso da RTP.

\footnotetext{
2 Para balizar a nossa observação procuramos considerar as seguintes categorias de análise: a) existência de integração no portal entre produtos de rádio e televisão tradicionais; b) existência de serviço de entrega de conteúdos on demand; c) existência de oferta de conteúdos em tempo real; d) linguagem utilizada para a apresentação multimídia; e) adoção de estratégias transmídia; f) uso de material de arquivo; g) existência de propostas de engajamento da audiência com mecanismos e estratégias utilizadas; h) estratégias de uso e participação da rede social; i) criação de comunidades de audiência; j) criação/disponibilização de aplicativos para aparatos móveis; I) desenvolvimento de produtos para interligar a mídia tradicional e o espaço da internet como jogos ou eventos.

${ }_{3}^{3} \mathrm{Na}$ EBC a entrevistada foi a Superintendente Executiva de Agências e Conteúdos Digitais, Denise Bacoccina. Na RTP o entrevistado foi o Diretor de Multimídia, João Pedro Galveias.
} 


\section{O CONTEXTO DA EBC: A CONVERGÊNCIA INCIPIENTE}

De modo geral, o portal da EBC expressa uma concepção de convergência em estágio bastante inicial diante das possibilidades técnicas disponíveis e utilizadas em outras entidades congêneres. A primeira consideração é sobre a arquitetura. As páginas do portal estavam estruturadas a partir de entradas para os sítios específicos de agências de noticias, rádios, televisão e ouvidoria da empresa e para encaminhar o usuário para áreas temáticas/informativas consideradas importantes pela EBC. O portal foi concebido a partir de um conceito tradicional: a separação dos canais embora eles coexistam no mesmo espaço. A ideia de separação dos serviços de rádio, TV e agências sinaliza um baixo índice de convergência.

A estratégia da empresa foi dar visibilidade a marca EBC, praticamente desconhecida do grande público. Dois projetos de portal foram desenvolvidos em menos 4 anos. No primeiro, entre 2012-2013, o foco estava em destacar na primeira página as notícias produzidas pela Agência Brasil, além de somente fazer chamadas das programações da TV Brasil e das rádios. Logo após o lançamento do portal, a empresa enfrentou restrição de divulgação de conteúdo. Apenas metade da programação da TV era de produção própria, enquanto a outra não possuía cláusula para web nos contratos de coprodução, o que contribuiu para inviabilizar sua exibição em diferentes plataformas.

Em 2014, o portal passou por nova reformulação técnica e visual com o objetivo de torná-lo responsivo, ou seja, com design flexível para se adaptar automaticamente em qualquer dispositivo (PC, celular, tablet, etc). A nova fase ainda estava em andamento em setembro de 2015, com a reformulação das páginas das rádios e da TV. No entanto, observou-se que ainda persistia a estratégia de separação de canais e o direcionamento para ser um portal de notícias produzidas, na sua maioria, pela Agência Brasil4. Os canais de rádio e TV continuavam sem visibilidade na primeira página do portal EBC. O usuário podia ouvir em tempo real, somente as rádios sob controle da empresa já que a TV Brasil, canal de sinal aberto transmitido para todo o país, ainda não tinha a sua programação em streaming. Somente a TV Brasil internacional era transmitida por meio da Web TV.

Outro aspecto é a baixa oferta de conteúdos on demand o que poderia ampliar o alcance de muitos produtos como séries, ficção, infantis, programas de rádio entre outros. Em parte, o problema estava relacionado a ausência de direito de imagem. No entanto, observou-se a entrega de poucos conteúdos jornalísticos próprios em áudio e vídeo integrado à narrativa baseada em texto e fotos ${ }^{5}$. Algumas poucas iniciativas multimídia já haviam sido desenvolvidas e estavam disponíveis na seção "Conteúdo Especiais". Embora seja louvável a iniciativa de produção de especiais, ela está longe de configurar uma narrativa transmídia entendida como aquela que se desenrola por meio de múltiplos

\footnotetext{
${ }^{4}$ A Agência Brasil é uma produtora de notícias de âmbito nacional da EBC, cujo conteúdo diário pode ser replicado gratuitamente em jornais e emissoras de rádios e TV do interior do país.

${ }^{5}$ A baixa integração multimídia foi explicada pelas limitações técnicas da empresa que não dispõe de ferramenta Content Delivery Network (CDN), uma rede de distribuição de conteúdos multimídia. Sem essa rede, a empresa teria de fazer manualmente a adaptação de vídeos em vários formatos para os diferentes tipos de dispositivos.
} 
canais de mídia, cada um deles contribuindo de forma distinta para a compreensão de um tema ou assunto. Alcança, sem dúvida, algum grau de crossmídia em parte da produção, mas falta efetividade, no geral, porque implica em reproduzir o conteúdo de várias mídias no mesmo lugar mas sem necessariamente adaptá-los.

Em relação às de formas de interação e participação do público, verificou-se que a EBC dispõem de páginas institucionais nas redes sociais e somente alguns programas de rádio e tv tinham páginas específicas nas redes sociais que permitiam a participação da audiência através de comentários.

No âmbito da oferta de aplicativos para aparelhos móveis como tablets ou smartphones, a presença da empresa é mais tímida ainda. Somente as emissoras de rádio dispõem de um aplicativo que permite ouvir a programação em tempo real. Nenhuma outra informação ou conteúdo é oferecido ou pode ser acessado pelo aplicativo. Não há qualquer ação no sentido de criar jogos ou eventos de promoção que estejam relacionados com os conteúdos da programação das emissoras de rádio e televisão da EBC.

Com exceção de alguns programas que apresentam páginas que se aproximam de uma linguagem multimídia, o portal como um todo - estrutura, texto, grafismo e visual - tem uma marca de natureza informativa. Dentro de nossa perspectiva, identifica-se mais como uma agência de notícias pautada pela cobertura de tipo do hard news, com destaque para fatos já divulgados em outros portais de notícias. A diferenciação que procura oferecer está na cobertura de alguns temas como cidadania, cultura, educação e meio ambiente. Porém, isso não significa, de fato, uma cobertura diferenciada. São raras as matérias que apresentam uma abordagem aprofundada e que são complementadas por recursos multimídia. O baixo índice de atratividade impede que se transforme em espaço de entretenimento e informação de qualidade, cumprindo, assim, alguns dos seus objetivos como prestador de serviço público.

\section{Desafios PARA A EBC}

Diante desse quadro, a perspectiva da gestora da EBC, Denise Bacoccina, é a de que a entidade ainda está "engatinhando" no processo de modernização tecnológica e de preparação para ocupar o espaço virtual. Essa perspectiva é resultante do próprio momento histórico da instituição, criada há pouco mais de oito anos e que ainda luta para se estabelecer e se consolidar como ente público de radiodifusão.

Apesar de um conjunto de dificuldades estruturais, o ente público vem ao longo dos últimos anos adotando medidas no sentido de avançar na modernização do seu portal e na forma de promover o acesso e oferecer conteúdos produzidos pelos seus canais de radiodifusão. A responsável pela multimídia da EBC afirma que o desafio maior é o de administrar o complexo processo que envolve a modernização do aparato virtual da entidade a partir da ideia de que não há recursos disponíveis para a realização de todo o leque de ações exigidas para que a empresa possa se fazer presente na internet de modo satisfatório. O que se busca é administrar da melhor forma o que gestora designa como a "estratégia do possível", situação que se materializa na necessidade de estabelecer 
prioridades na fila de ações que devem ser realizadas para uma ocupação positiva do espaço virtual pela EBC.

Para isso, o setor tem lutado para conquistar recursos financeiros que garantam um mínima modernização do portal e feito esforços no sentido de que haja uma continuidade de planejamento e ações voltadas para a operação da EBC na rede. A gestora acredita que é necessário o estabelecimento de uma política de administração que defina claramente as etapas e responsabilidades a serem executadas no processo de atualização, bem como, ter um desenho claro de quem faz o que nesse processo. Nessa perspectiva, entende ser fundamental institucionalizar um setor e estabelecer um corpo de profissionais ${ }^{6}$ de produção de conteúdos e de tecnologia da informação que sejam estáveis e que possam assim, desenvolver um corpo de saberes e conhecimentos sobre a área a serem utilizados para a melhoria da estratégia e da atuação digital/virtual da empresa.

Outro desafio estrutural é o de desenvolver aplicativos da entidade. Na sua opinião, a EBC está bem atrasada neste campo e ainda não possui aplicativos com a devida qualidade para que sejam amplamente disponibilizados para o público. A busca por recursos para esta ação é a grande luta que está sendo realizada no momento, pois segundo ela, dentro da instituição já existe a compreensão da importância em desenvolver recursos tecnológicos dessa natureza em face do acentuado incremento no uso de aparatos móveis no Brasil e no mundo de modo geral. Para ela, o maior obstáculo que se apresenta nesta área não é a falta de visão sobre a questão e sim as dificuldades financeiras e operacionais em executá-la.

Denise Bacoccina ainda indica que outra grande meta é a de conseguir estabelecer um processo de trabalho dentro desse novo ambiente de produção que esteja baseado em objetivos claros, coerentes, realistas e mensuráveis. A partir da constatação dos problemas estruturais que existem na empresa, ela afirma que a EBC ainda não está preparada para o estabelecimento de metas a longo prazo. Ainda não se tem na instituição, um horizonte claro dos objetivos e estágios a serem alcançados e, principalmente, a forma como isso será feito. Há uma grande dificuldade em analisar um contexto mais complexo, superar entraves burocráticos e definir metas para um ambiente dinâmico no qual três, quatro ou cinco anos acabam sendo muito tempo, considerando o dinamismo do ambiente virtual.

Outra dimensão desafiadora para a entidade é de ordem técnica e também conceitual sobre como pensar e elaborar - ou reelaborar - o seu atual portal. O portal foi pensado inicialmente como um hub para o qual convergiriam conteúdos elaborados tanto pelos profissionais da empresa quanto por colaboradores externos com os quais a entidade manteria relações. A partir dessa perspectiva, o que se estabeleceu foi um portal composto por áreas isoladas dedicadas a entrega de conteúdos desenhados a partir de meios específicos da empresa como as rádios, a televisão e a agência noticiosa.

Outro motivo para que isso tenha acontecido é o fato de que a noticia sempre foi pensada como um conteúdo privilegiado a ser ofertado pelo site da EBC. Segundo ela "a

${ }^{6} \mathrm{~A}$ EBC chegou a ter 20 profissionais dedicados ao desenvolvimento de ações em $\mathrm{Tl}$ e no momento da entrevista a gestora indicou que somente três profissionais se dedicavam a cumprir as tarefas neste setor. 
noticia é a coisa mais nobre da própria EBC e é parte fundamental da sua missão como ente público". A partir dessa concepção e considerando que a Agência Brasil sempre foi uma marca forte da própria EBC e, por isso, vista dentro da entidade como um "veículo em si mesmo" e diferenciado dos demais, o site adquiriu a perspectiva informativa/noticiosa que apresenta atualmente. A gestora acredita que outro fator que influi para que o noticioso tenha preponderância no portal, é o fato de que os meios da entidade têm que oferecer o chamado hard news em suas programações cotidianas. Portanto, o desafio que se apresenta é pensar, a partir da situação que definiu como "privilégio da notícia", a maneira como a instituição transformará essa predominância de conteúdos informativos de modo a incorporar ao portal outros tipos de conteúdos que são produzidos pela EBC e demandados por segmentos específicos do público.

Para isso, é fundamental que haja uma reflexão sobre esse tema, de modo a que se repense as bases conceituais que regem e estabelecem os parâmetros que definem a importância dos conteúdos noticiosos e de entretenimento que a EBC produz e que orientam suas ações para o cumprimento de sua missão. A entidade e a sua "massa crítica profissional" devem possuir uma visão e entendimento de como o fluxo de informação, tanto na produção quanto na entrega, está se transformando. Um fluxo de informação e de acesso ao conteúdo que não ocorre mais pela mera aderência a um portal mas sim pelo interesse em acessar conteúdos diversos por parte dos usuários.

Essa situação expressa uma disruptura de plataforma, ou seja, a importância está no conteúdo e na capacidade de fazer com que o seu acesso esteja disponibilizado na rede e não somente no acesso aos sites institucionais, as chamadas homes. Indica também que a importância não está somente na produção de conteúdos mas sim, naquilo que se consegue entregar ao público e nos canais pelos quais esta entrega acontece. Para ela, o objetivo final desse processo de reflexão deve ser o de elaborar um portal que ultrapasse o estágio atual que ainda expressa um modo de ver a produção de conteúdos virtuais fragmentada e sem a especialização de formatação e de linguagem. Segundo ela, o desafio é de bem escolher os conteúdos que vão para a WEB e de tirá-los das caixinhas nas quais foram colocados considerando que a rede acaba estabelecendo um processo por ela denominado de "gourmetização do conteúdo", ou seja, a possibilidade de entregar conteúdos trabalhados de modo específico e ao gosto dos distintos perfis de "clientes" que transitam pela rede.

A gestora da EBC, Denise Bacoccina, afirma ainda, que outro grande desafio para a instituição é elaborar um sistema de recolhimento e avaliação de dados coletados a partir de como o portal da EBC é utilizado pelos usuários. Para ela é extremamente importante acumular e, principalmente, compreender uma quantidade representativa de informações, não só de natureza quantitativa mas, sobretudo, qualitativa a respeito dos desejos e interesses que movem os usuários nos ambientes das redes e, especificamente, o que os impele a acessar o portal da EBC. Esse conjunto de informações será importante para gerar conhecimentos e leituras que irão colaborar decisivamente para o estabelecimento de estratégias que orientem a produção e a forma de ofertar os conteúdos ao público usuário. As informações básicas que já começaram a ser coletadas sobre os usuários, 
ainda que de modo bastante limitado, produziram resultados considerados significativos já que permitiram criar condições para melhor promover perante o público o acesso aos conteúdos disponibilizados pelos meios da instituição, situação que favoreceu a ampliação de acessos mensais de 100 mil para pouco mais de dois milhões de usuários.

Ainda deve ser enfrentado outro desafio de natureza técnica que é fazer com que todo o site seja responsivo7, ou seja, esteja habilitado para ser acessado por intermédio de dispositivos móveis como, por exemplo, os aparelhos celulares. O site da EBC tornou-se foi transformado em responsivo somente no ambiente definido para as notícias, privilegiadas mais uma vez. Agora há a necessidade de dotar os outros conteúdos que podem ser oferecidos para celular, o que melhora a qualidade de acesso e amplia as suas possibilidades, já que os usuários que desejam acessar o site nos ambientes que não são apresentados de forma responsivos ainda são levados para as partes antigas do portal, piorando muito o padrão de qualidade de acesso oferecido aos usuários. É um desafio a ser enfrentado em face da falta de recursos.

Outra dimensão desafiadora é a de promover uma transformação na cultura profissional das distintas áreas da entidade, fomentando ações e perspectivas que promovam a interação das atividades de produção de conteúdos. Desde a criação da área de multimídia que ocorreu em 2014, o desafio tem sido na direção de inovar a visão dos profissionais da casa sobre as próprias áreas e suas relações com o ambiente virtual, inovação esta que possa chegar ao próprio portal como resultado final, superando a segmentação de funções que ainda existe. Para isso, é necessário conseguir a adesão dos profissionais para fazer com que se expanda uma mentalidade que considere os meios públicos como espaços de inovação na oferta de conteúdos. As inovações na forma de produzir conteúdos estão exigindo que o profissional tenha várias habilidades para a produção e essa exigência tem trazido alguns conflitos para o ambiente profissional e, consequentemente, para a própria empresa. Segundo Denise Bacoccina é necessário que técnicos, radialistas e jornalistas da EBC modifiquem sua visão sobre os limites legais estabelecidos para o exercício profissional e ultrapassem as resistências de natureza classista e corporativa que surgem no ambiente laboral.

A gestora defende ainda que a empresa estabeleça uma política sustentável de treinamento que promova a reciclagem dos seus profissionais de modo que possam ampliar o espectro de formação e estarem assim, preparados para atuarem de maneira diversificada. Na mesma direção, ela defende a necessidade de criar grupos de jovens profissionais com novas ideias e liberdade criativa, com o objetivo de estabelecer um espaço de estudo, criação e experimentação de novas linguagens a serem utilizadas na formatação de conteúdos. Para ela, estes grupos seriam potenciais criadores de estratégias mais eficazes para produzir os conteúdos da EBC para os segmentos mais jovens do público.

E para finalizar, a gestora afirma que um dos desafios mais importantes a ser enfrentado pela EBC é o de conseguir desenvolver uma velocidade nos seus processos

7 É uma solução técnica que programa um site de forma que os elementos que o compõem se adaptem automaticamente à largura de tela do dispositivo móvel no qual ele está sendo visualizado. 
administrativos, jurídicos e de produção que sejam suficientemente compatíveis e eficazes para lidar com as contínuas demandas geradas pelo ambiente virtual de modo a que não sejam suplantados pela velocidade do processo tecnológico, gerando um funcionamento precário e pouco dinâmico.

\section{RTP: CONVERGÊNCIA EM EVOLUÇÃo}

O portal da RTP apresenta características básicas que demonstram a presença bem mais consolidada de estratégias convergentes na sua produção. A oferta de bons aplicativos para dispositivos móveis, a lógica da arquitetura, o design e a política editorial adotada expressam princípios convergentes. Oferece em tempo real acesso as programações de seus canais tradicionais de radiodifusão, permite personalização de acesso por tipos de conteúdos preferidos, disponibiliza uma série de entradas para outros sítios oferecidos pelo portal que ampliam a oferta de informação e de conteúdos de entretenimento tais como áreas de documentais, séries dramaturgias e programas de arquivos entre outros. Percebe-se que a página de entrada é, de fato, pensada a partir de uma arquitetura que a transforma em uma vitrina na qual estão expostos e organizados conteúdos e veículos que podem ser explorados direta e rapidamente pelo usuário ao bel-prazer de seus gostos e necessidades.

Parte dos conteúdos já está formatada para Internet mesmo que tenha origem nos meios tradicionais da RTP, situação que pode ser ilustrada pelas matérias especiais disponibilizadas no portal. Também se faz uso intensivo de material histórico e audiovisual que a entidade guarda em seu vasto arquivo. É evidente que o objetivo de apresentar os conteúdos de modo amplo, variado e dinâmico é fazer com que a atenção da audiência seja capturada a partir de um conjunto de chamadas que servem como "iscas" para que se consiga, de alguma maneira estabelecer identificação entre os distintos desejos e interesses de consumo informativo e de entretenimento dos seus usuários e os conteúdos que o portal oferece. Nessa mesma direção, disponibiliza amplo acesso a conteúdos on demand em áudio e vídeo.

Nas páginas dedicadas aos programas de rádio ou televisão, os conteúdos gerados pelos comentários do público ainda não se configuram em ações que estejam colaborando para desenhar, dentro do portal, universos mais trabalhados sobre os referidos produtos. A maioria dos espaços disponibiliza formas de participação por meio das redes sociais - apenas comentários - e, notadamente, o portal oferece acesso a partes dos programas ou a versão integrais dos mesmos. Não se vislumbra uma ação que permita e incentive a participação do público de forma mais ativa no acompanhamento dos sites dedicados aos programas que mais gosta. Ainda não há, como em outros sites de entes públicos europeus, uma ação contínua que configure, de modos distintos, uma espécie de comunidade de ouvintes ou espectadores que apresentam afinidades a determinados conteúdos e produtos e que podem participar de atividades diversas relacionadas com os conteúdos e personagens de séries e programas que admira. Mesmo assim, na RTP esse movimento de contato mais ativo com o público já pode ser percebido, ainda 
que em menor escala, por meio da criação de aplicativos que permitem, em tempo real, a participação do público diretamente em programas e o estabelecimento de contato entre os próprios membros da audiência como o já utilizado no programa The Voice Portugal. As ações neste sentido ainda são pontuais.

O portal da RTP já apresenta características típicas da convergência. Já faz uso de diferentes linguagens e formatos para apresentação de conteúdos, oferece design e navegação dinâmicos e interativos em boa medida. Mais do que evolução técnica e expressiva convergência, o portal evidencia a busca por estabelecer uma estratégia cujo objetivo é a adaptação continua às constantes inovações da Internet, buscando para isso, desenvolver, cada vez mais, a capacidade de integrar os conteúdos produzidos pelos seus veículos da mídia tradicional ao ambiente digital, reinventando e criando novos formatos e linguagens para seus conteúdos. Processo que, por certo, está instituindo formas inovadoras e criativas da RTP relacionar-se com suas potenciais audiências virtuais.

\section{DESAFIOS PARA A RTP}

Segundo o diretor de multimídia da RTP, João Pedro Galveias, a entidade vem realizando ações neste setor nos últimos 25 anos. Ao longo de mais de duas décadas, a RTP passou por várias fases no desenvolvimento de sua área multimídia, momentos que foram marcados por crises institucionais, limitações orçamentárias e transformações no desenho interno da entidade ${ }^{8}$. Desenho este que, depois de passar por várias situações, determinou a existência de um setor específico na entidade, precisamente em 2006, para pensar e elaborar os conteúdos denominados como multimídia e ofertados por meio do seu portal na internet.

O conjunto de desafios que se apresentam é amplo e caracterizado por ações que visem organizar e institucionalizar o funcionamento do setor da RTP que cuida e pensa sua produção digital/virtual. O gestor de multimídia defende que em uma entidade com o tamanho e os setores que possui a RTP, é fundamental estabelecer uma diretoria para centralizar e gerenciar a produção de conteúdos multimídia. Do contrário, esse tipo de ação tenderá a ficar fragmentada, dispersa e antiquada. Na sua perspectiva, a manutenção de um setor específico para a produção dirigida para o universo virtual é o melhor sistema para promover a integração dos diversos setores que podem colaborar para a elaboração de produtos voltados para a internet. Para ele, a entidade e seus profissionais devem ter consciência e trabalhar com a ideia de que há um novo "ecossistema multimídia" que está impactando e afetando cada vez mais a vida das pessoas em geral e, inclusive, dos próprios profissionais ligados à comunicação e ao seu cotidiano de produção.

A RTP deve estar preparada para utilizar os seus recursos de produção tradicionais como o rádio e televisão na concepção e elaboração de conteúdos nesse terceiro novo

\footnotetext{
${ }^{8}$ Para a análise dos desafios que se apresentam perante a RTP, é importante considerar que nos últimos anos a entidade enfrenta uma situação bem mais favorável no que concerne ao seu financiamento a partir da adoção da chamada Contribuição do Audiovisual que é paga pelo cidadão na sua conta de energia elétrica. Esses recursos dotaram a instituição de condições bem mais estáveis para estabelecer um planejamento realista e crível para a sua manutenção e para o seu desenvolvimento nesse novo universo da mídia virtual.
} 
setor que pode agregar, de forma inovadora, todos os elementos básicos de linguagem dos demais meios. Ou seja, há de ser entendido pelos dirigentes e profissionais da RTP - assim como acontece nos demais meios de comunicação privados - que o produto a ser oferecido ao público no espaço da rede é, e deve ser, muito mais do que um programa de televisão ou de rádio.

O gestor de multimídia, João Pedro Galveias, defende a ideia de criar projetos que busquem e incentivem a criatividade por meio de ações inovadoras na criação de novas plataformas a serem disponibilizadas pelo portal e cita como exemplo a ideia de reunir jovens profissionais de jornalismo ou do entretenimento para elaborarem novas propostas de conteúdos e novas maneiras de disponibilizá-los aos públicos. Estes novos profissionais conhecem e utilizam esse ambiente com maior desenvoltura. No entanto, ele alerta para a necessidade dos profissionais assumirem uma postura de humildade diante da realidade tecnológica que facilita cada vez mais o uso de recursos. Os profissionais não devem confundir a habilidade de uso dos recursos com o conhecimento técnico específico. Isso seria uma simplificação do desafio tecnológico que se apresenta para os profissionais do setor. Há de se ter consciência de que o fato de ser um usuário avançado nem sempre garante ao profissional a clareza de saber o que fazer na criação de recursos virtuais. Usar os recursos é uma coisa e saber o que fazer claramente em nível profissional é outra. A base dessa postura é a ideia de que há que estabelecer uma cultura institucional para criar e experimentar, com espaço para o equívoco e a incerteza do sucesso.

Nesse cenário, um importante desafio para a RTP é manter, ao longo do tempo e, de modo estável, a formatação de uma diretoria multimídia dentro de sua estrutura administrativa. A manutenção desse setor é importante para que se possa estabelecer novos desenhos de produtos a partir de processos de estudo e de experimentação; para obter um grau de liberdade editorial na confecção desses materiais já desvinculados de outros setores tradicionais da entidade; para poder desenvolver um corpo de funcionários que adquiram e desenvolvam competências específicas de produção de conteúdos e também para o desenvolvimento de tecnologias que sustentem o funcionamento do portal da entidade e otimizem o desenvolvimento de sistemas próprios que garantam, de modo autônomo, a oferta de recursos inovadores para a disponibilização de conteúdos e para a interação com usuários.

Para o gestor da RTP, a instituição ainda está formando e preparando, neste momento, equipes que elaborem produtos a partir da perspectiva multimídia de produção de conteúdos. Na sua visão estão se desenvolvendo, pouco a pouco, ações em duas dimensões: uma relativa ao desenvolvimento de recursos técnicos na instituição e ao processo de capacitação dos seus profissionais para manipulá-los de forma eficaz, competente e criativa, e outra relativa a estruturação institucional que garanta que o processo de trabalho que está se instaurando nesta área, seja perene dentro das rotinas pensadas para a entidade. $O$ desafio está em criar dentro desse segmento uma espécie de unidade de produção de programa, ou seja, espaços nos quais todas as competências técnicas que possuem os canais da entidade estejam reunidas, de modo articulado, para atender 
as exigências que a produção multimídia apresenta. Defende ainda, que o conteúdo seja resolvido na origem a partir da ideia de que o profissional que atua no multimídia deve ter a capacidade de produzir diversos formatos/linguagens para o digital, inclusive.

Outro importante desafio é garantir que haja recursos previstos no orçamento da entidade para cumprir o que ele chama de a "criação de uma nova mídia", ação que atribui como missão à RTP. Na sua perspectiva, há que desenvolver duas correntes de ação no ente público. Uma para elaborar a mídia de hoje e outra pensar a mídia do futuro. Isso é um desafio em face de que serão públicos diferentes para os quais os produtos deverão estar voltados. Como exemplo, João Pedro Galveias cita que os profissionais atuais de mídia devem lidar com o fato de que "fenômenos televisivos" com impactos em audiências massivas, estão cada vez mais raros para o público jovem. Diante do uso intensivo dos aparatos móveis e do ambiente virtual, o desafio será elaborar um modelo de produção que produza conteúdos mais baratos e com menos impacto de audiências, ao contrário do modelo que ainda impera na radiodifusão tradicional. Por isso, ele acredita que a entidade deve oferecer a mídia tradicional ao público, de forma generalista, mas também, simultaneamente e de maneira desafiadora, tem a obrigação de pautar suas ações pela inovação, oferecendo as novidades midiáticas a esse mesmo público por meio da rede.

Segundo o gestor da RTP, o desafio é manter o setor multimídia da entidade em uma espécie de "posição de combate", ou seja, atuar de modo a que a própria entidade não perca de vista o trabalho feito por este setor. A estratégia é promover um processo que reitere continuamente, e perante toda a RTP, a existência e a presença do setor e dos conteúdos que elabora. Isso é um verdadeiro processo de luta pela visibilidade do setor perante a instituição. Considera isso importante como forma de também lidar e lutar contra a enorme desproporção que existe entre o setor de radiodifusão tradicional e o digital/virtual. Para se ter ideia disso, ele afirma que a unidade multimídia da instituição possui pouco mais de 20 profissionais trabalhando, e nem todos do quadro da RTP, diante de pouco menos de 1700 funcionários no total ${ }^{9}$. Ele indica que o número ideal de pessoas trabalhando na multimídia deveria estar ao redor de 150.

Outro desafio apontado é que ainda não há um grau de institucionalização das ações do setor que permita estabelecer metas ou parâmetro de desenvolvimento a serem alcançados a curto e médio prazos. Também não existe um sistema de métricas, que recolha desde dados quantitativos de audiências e acessos até o recolhimento de informações qualitativas sobre os usuários que buscam o portal da instituição, seus desejos e posturas. Esse é um desafio importante pois a partir da composição e alimentação de bancos de dados que delineiem perfis dos usuários, será possível pensar e elaborar um conjunto de estratégias voltadas para a produção de conteúdos demandados por segmentos de públicos atendidos pela instituição. Para lograr esse objetivo o gestor da RTP afirma que será necessário aportar recursos que garantam o estabelecimento das estruturas técnicas, operativas e profissionais para sustentar a necessária pesquisa e desenvolvimento tecnológico. Nessa mesma direção, o gestor da RTP defende como um

\footnotetext{
${ }_{9}$ Dados retirados de http://www.atelevisao.com/rtp/rtp-volta-a-reduzir-numero-de-trabalhadores/.
} 
primeiro e possível passo a ser dado a criação de uma zona de subscrição de usuários no portal da entidade.

Finalmente, indica a necessidade de criar uma estrutura técnica e de pessoal para acompanhar o que ocorre, especificamente, nas redes sociais e observar as tendências que estão surgindo nesses espaços. Ele afirma que não há forma de controlar ou determinar o que ocorrerá nesses ambientes. O segredo para tentar conquistar relevância nesses universos é conseguir pensar e produzir um bom produto que tenha algum nível de repercussão - propagabilidade - e gere, principalmente, interesse entre usuários.

\section{ConclusÃo}

O que podemos observar através dos gestores é que os desafios são grandes e exigem, de muitas maneiras, que as instituições se reinventem para "fincar suas bandeiras" no terreno delineado e altamente disputado da "rede de redes". As entrevistas demonstraram que uma perspectiva comum encontrada é a de que o desafio essencial a ser afrontado é promover uma mudança de mentalidade no funcionamento dos entes públicos. Será necessário realizar um trabalho político e de sensibilização das estruturas de administração, de seus diretores e dos membros de seus conselhos com poder de decisão, no sentido de que tenham consciência e informação sobre as transformações que estão ocorrendo na comunicação/radiodifusão a partir do desenvolvimento e incorporação, cada vez mais rápida e intensiva, das tecnologias digitais de informação. Somente a partir dessa atuação esclarecedora e de conscientização do potencial de alcance que as entidades podem obter ao atuarem na internet, é que se tornará possível a institucionalização sustentável de setores multimídia e a natural disputa por recursos em uma entidade que tem a obrigação de oferecer a população um serviço de informação e entretenimento que, atualmente, pode ser entregue de duas formas, ou seja, pelo sistema tradicional da radiodifusão ou através do ambiente virtual.

Essa conscientização significa muito e é considerada como fundamental para que outras tantas mudanças possam ser implantadas. Torná-la realidade é altamente complexo em face das múltiplas modificações que o trabalho no ambiente virtual exige das instituições e de seus quadros funcional e diretivo. As alterações devem ser de ordem funcional tanto no ambiente administrativo quanto na produção de conteúdos. Além disso, é prioritário que essas mudanças produzam reais repercussões no sempre conturbado ambiente financeiro das entidades, garantindo recursos do orçamento para as atividades que devem ser desenvolvidas pelos setores de multimídia.

Para os gestores outro grande desafio é fazer com que as entidades superem o estágio da radiodifusão tradicional e seus modi operandi e consigam dar um salto para uma nova etapa ao agregarem uma mentalidade renovada e, consequentemente, remodelarem seus métodos de trabalho, de produção e de distribuição, agora voltados também para o desenho e a elaboração convergente de produtos informativos e de entretenimento destinados ao consumo no universo virtual.

Para isso, os gestores defendem uma postura assumida pelos seus setores que é o de fazerem-se notar nas estruturas das suas entidades e de lutarem para promoverem 
mudanças na leitura estratégica que estas entidades realizam do cenário atual e futuro de formação de público, valorizando as transformações que tem acontecido na forma de produzir e formatar conteúdos multimídia e, de maneira muito especial, estar atenta as modificações no modo de consumo e acesso a esses produtos.

Outro desafio importante é a mudança de cultura que deve ocorrer com os profissionais. As mudanças requeridas são amplas e devem alterar desde concepções e processos de trabalho na elaboração de conteúdos até a perspectiva que os próprios profissionais de produção possuem de suas habilidades, possibilidades e limites de atuação. Nas entrevistas os gestores deixam claro que o ambiente de inovação, dinamismo e de uso de recursos de linguagem variados (imagem, texto e som) impõe aos profissionais uma transformação que se choca com limites antigos que demarcam possíveis habilidades e tarefas a serem cumpridas por um determinado tipo de profissional. Um profissional que atua nessa área deve superar a compartimentalização de funções e produzir de áudio a imagem, sem distinção. Dito de outra forma, um produtor multimídia deve ser de fotógrafo a repórter que produz matérias de áudio ou de imagem.

Nessa direção, nos parece que os gestores têm buscado pensar e, sobretudo, garantir a criação e manutenção estável de departamentos e de plantéis mínimos de profissionais especificamente destinados a pensar e administrar o relacionamento da entidade com os seus potenciais públicos virtuais, acompanhando a dinâmica desse universo e recolhendo dados que demonstrem as posturas, críticas, elogios, desejos e demandas que as audiências apresentam e que podem ser utilizados positivamente pelos entes públicos para orientarem suas estratégias de produção e também potencializar a divulgação e o conhecimento de seus produtos por parte da própria cidadania que está presente nas redes e que dela faz uso. Cumprindo também um de seus objetivos como instituição pública de comunicação, ou seja, estar disponibilizada para a maior quantidade de pessoas.

É no cenário de mutações que a EBC e a RTP precisam agir. Entre seus complexos desafios, acreditamos que o estabelecimento, a médio prazo, de uma estratégia virtual, minimamente articulada, é um dos mais importantes a ser enfrentado em face do que já ocorre no presente e do futuro que se perfila para a radiodifusão a partir do incremento da "vida virtual". Esse conjunto de ações poderá ser um instrumento fundamental para que as instituições promovam a difusão de suas marcas e de seus produtos/conteúdos entre distintos segmentos de públicos, notadamente os mais jovens, que até o momento já apresentam significativa distância dos canais tradicionais da radiodifusão. As manifestações dos gestores demonstram que as entidades devem lutar contra impossibilidades gerenciais, financeiras, operacionais, políticas e de culturas profissionais arcaicas materializadas nas próprias culturas institucionais que terminam sendo resultantes das distintas mentalidades administrativas e técnicas existentes nos ambientes dessas instituições, de modo a superar as inseguranças e resistências que tradicionalmente tendem a marcar os processos de profunda inovação e transformação, como os que o momento atual provoca na radiodifusão. 
Somente a partir desse enfrentamento em cada um dos cenários institucionais, é que EBC e RTP poderão modificar, incorporar e cristalizar novos parâmetros de produção e novos protocolos que orientem seus métodos de trabalho e elaboração de distintos conteúdos midiáticos voltados para o ambiente virtual. Situação que poderá permitir, paulatinamente, o aprofundamento da presença das instituições nas redes e a consequente obtenção de possíveis ganhos significativos para a representatividade e legitimidade social e para a sobrevivência dos entes públicos analisados neste artigo.

\section{REFERÊNCIAS BIBLIOGRÁFICAS}

Arons de Carvalho, A. (2009). A RTP e o serviço público de televisão. Coimbra: Edições Almedina.

Benvenido, L. (2012). La televisión ante el desafío de internet. Salamanca: Comunicación Social Ediciones y Publicaciones.

Bianco, N. R. D., Esch, C. E. \& Moreira, S. V. (2012). Radiodifusão pública: um desafio conceitual na América Latina. Estudos em Comunicação, 12, 155-181.

Bustamante, E., Franquet, R., García Levya, T., López, X. \& Pereira, Y. X. (2008). Alternativas en los médios de comunicación digitales - Televisión, radio, prensa, revistas culturales y calidad de la democracia. Barcelona: Gedisa.

Bustamante, E. (2003). Hacia un nuevo sistema mundial de comunicación - Industrias culturales em la era digital. Barcelona: Gedisa.

Cardoso, G (2007). A mídia na sociedade em rede. Rio de Janeiro: Editora FGV.

Coutinho, M. (2006). Movimentos de mudança política na América do Sul contemporânea. Revista de Sociologia e Política, 27, 107-123.

Fuenzalida, V. (1998) Situación de la televisión pública en América Latina. Diálogos de la comunicación, 53, 89-119.

Graván, M. L. (2012). El futuro de la Televisión Pública. La necesaria alianza con la ciudadanía. Madrid: Editorial Popular.

Jenkins, H. (2015). Cultura da convergência. São Paulo: Editora Aleph.

Jenkins, H., Green, J. \& Ford, S. (2014). Cultura da conexão - criando valor e significado por meio da mídia propagável. São Paulo: Editora Aleph.

Mateo Pérez, R. \& Bérges Saura, L. (2009). Los retos de las televisiones públicas: financiación, servicio público y libre Mercado. Sevilla: Comunicación Social Ediciones y Publicaciones.

Mendel, T. (2011). Serviço público de radiodifusão: um estudo de direito comparado. Brasília: UNESCO.

Moraes, D. (2009). A batalha da mídia - Governos progressistas e políticas de comunicação na América Latina e outros ensaios. Rio de Janeiro: Pão e Rosas.

Serra, P. (2015). A televisão ubíqua. Covilhã: UBI.

Wolton, D. (2006). Elogio do grande público: uma teoria crítica da televisão. São Paulo: Ática. 


\section{OUTRAS REFER̂̂NCIAS}

Unesco (2001). Public Broadcasting: Why? How? Retirado de http://unesdoc.unesco.org/ images/0012/001240/124058Eo.pdf

\section{ENTREVISTAS PESSOAIS}

Bacoccina, Denize (2015). Brasília, 28-08-2015.

Galveias, João Pedro (2015). Lisboa, 16-09-2015.

\section{FinANCIAMENTo}

Trabalho acadêmico apoiado pela Fundação CAPES, no âmbito do acordo de cooperação CAPES/FCT através da realização de estágio pós-doutoral na Universidade do Minho em Braga.

\section{NOTAS BIOGRÁFICAS}

Carlos Eduardo Esch realizou estágio pós-doutoral na Universidade do Minho. É Doutor em Sociologia e Ciências da Comunicação pela Universidade Complutense de Madri. Professor da Faculdade de Comunicação da Universidade de Brasília e do seu Programa de Pós-graduação. Pesquisador do Laboratório de Políticas de Comunicação da UnB (LAPCOM). Fundou e coordena o Observatório da Radiodifusão Pública na América Latina da UnB.

Email: caduesch@hotmail.com

Universidade de Brasília

Programa de Pós-Graduação em Comunicação

ICC Norte, Bloco A, subsolo

Brasília-DF, 70910-900, Brasil

Mariana Martins de Carvalho é Doutora em Comunicação Social pela Universidade de Brasília (UnB), com estudos na área de políticas de comunicação e cultura e ênfase na comunicação pública. Pesquisadora do Laboratório de Políticas de Comunicação da UnB (LAPCOM). Gestora em Comunicação Pública da Empresa Brasil de Comunicação.

Email: marimartins.pe@gmail.com

Empresa Brasil de Comunicação

Setor Comercial SUL - SCS Quadra o8 Bloco B-6o

$7^{\circ}$ Piso Inferior - Edifício Venâncio 2000 - Asa Sul

Brasília/DF, 70333-900, Brasil

* Submetido: 8-03-2016

* Aceite: 10-04-2016 